\title{
Collaborative Research Trends and Authorship Patterns in North Eastern Hill University from 2000 to 2010
}

\author{
Khrawbok Nongrang \\ Research Scholar, Department of Library \& Information Science, North Eastern Hill University, Umshing, Mawlai, \\ Meghalaya, India \\ E-Mail: nongrangkhrawbok@gmail.com
}

\begin{abstract}
Authorship trends and collaborative research are studied in the North Eastern Hill University (NEHU) based on the data collected from Annual Report and NEHU Institutional Repository published during the year 2000-2010. Outcome of the study shows that multi authored articles $64.93 \%$ prevail the single authored articles $35.07 \%$. The degree of collaboration in NEHU is 0.65 . Average number of authors per paper varies from 2.29 to 3.44 . In 10 years from 2000 to 2010 the average no. of authors per paper is 2.72. . This study is in support for the fact that NEHU faculty members preferred collaborative trends for their research and publication work.
\end{abstract}

Keywords: Authorship Pattern, Collaborative Research, North Eastern Hill University, Publication Trends.

\section{INTRODUCTION}

Authorship Pattern describes author characteristics and authorship of articles with degree of collaboration of a specific group of authors. According to $\mathrm{Lai}^{[2]}$ collaborative research is termed as collaboration research by definition is termed as "mutual participation researchers in a coordinated effort to sort out the solution of a problem together." Collaborative interactions are characterized by shared goals, symmetry of structure, and a high degree of negotiation, interactivity, and interdependence. Roschelle ${ }^{[6]}$ frames collaboration as an exercise in convergence or construction of shared meanings and notes that research on conversational analysis has identified features of interactions that enable participants to reach convergence through the construction, monitoring, and repairing of shared knowledge. Authorship pattern and productivity are the important parameters in order to study citation analysis. Generally authorship of the article or document has become important for scientists and researchers in order to make out the author productivity and authorship pattern, the analysis of nature of research collaboration in research activity is prime factor. In the present study, collaboration research trends in North Eastern Hill University (NEHU) are studied from the period of 2000 to 2010. The main focuses in present communication are 'to study trends of authorship pattern, single versus multi authored articles and measure the degree of collaboration.

\section{OBJECTIVES OF THE STUDY}

The present study has been taken to identify collaborative research trends and authorship patterns in North Eastern Hill University from 2000 to 2010. The objectives of the study are as follows:

1. To study the growth of literature in NEHU

2. To examine and analyze the authorship pattern in NEHU

3. To study the proportion of single authorship Vs multiple authorship in NEHU

4. To determine the degree of collaboration

5. To find out the average number of authors per article in NEHU

\section{METHODOLOGY}

For the purpose of this study consulting the annual reports of NEHU of the last ten years from 2000 to 2010 this help in finding out about the publications by the faculty members of NEHU and to substantiate the study NEHU institutional repository is used to collect all the articles published by all the faculty members. Each published article has been analyzed to record the details of the title, author and no. of authors. The data collection was done manually and promote for tabulation year-wise.

\section{IV.LITERATURE REVIEW}

Sevukan and Sharma ${ }^{[7]}$ attempted to identify the nature of authorship pattern in scientific research output made by the Faculties of Biotechnology in central universities of India. It is evident that two-authored papers rank first in order sharing 33.73 per cent of the total research output. The year-wise analysis shows that the performance of twoauthored papers has been increasing in almost all the years except for 2000 and 2004. The three-authored papers follow second in order taking 24.92 per cent of the total research contributions followed by four- five- and six-authored contributions sharing 19.15 per cent, 11.55 per cent, and 5.17 per cent of the total scientific research output during the study period. Patra, Bhattacharya and Verma ${ }^{[5]}$ in their bibliometric study of literature on bibliometrics showed that about 4,000 authors publish 3,781 articles, which is 0.94 
articles per author. It means single authorship is very common in this field. About 3,106 (77.65\%) authors have only one publication and 470 (11.75\%) authors have two publications. The literature of D-Lib Magazine was studied by Park ${ }^{[4]}$ which covered a period of thirteen years and the data were collected by examining issues from July 1995 to May/June 2008. The findings proved that, two and more author's contribution was highest with a ratio of $57 \%$ and most of the authors had a single contribution. Panda, Maharana and Chhatar ${ }^{[3]}$ in their study on the journal of information literacy: a bibliometric study showed that the highest number of papers, i.e. 90 (68.7\%) are by single authors. Two and three authored contributions count is 23 (17.57\%) and 12 (9.16\%) respectively. The number of joint contributions by four or more authors is found to be 5
(3.81\%). It is evident that, over the years level of collaboration is very low in the case of publications in JIL. Jain and Kumar ${ }^{[1]}$ studied the research productivity of Indian Scientists contributing to world soybean research for the period 1989-2008 and found that most of the authors attained the low dominance factor value.

\section{RESULTS AND DISCUSSION}

The details of the no. of articles during 2000-2010 are presented in table 1 . It was found that the highest no. of articles were published in year 2009-2010 i.e. is 335 or $20.32 \%$ of the total articles whereas lowest no. of articles were published in year $2000-2001$ i.e. 83 or $5.03 \%$ of the total articles.

Table 1: Year-Wise Distribution of Articles

\begin{tabular}{|c|c|c|c|c|c|c|c|c|c|}
\hline Year & $\begin{array}{c}\text { Articles/1 } \\
\text { Author }\end{array}$ & $\begin{array}{c}\text { Articles/2 } \\
\text { Author }\end{array}$ & $\begin{array}{c}\text { Articles/3 } \\
\text { Author }\end{array}$ & $\begin{array}{c}\text { Articles/4 } \\
\text { Author }\end{array}$ & $\begin{array}{c}\text { Articles/5 } \\
\text { Author }\end{array}$ & $\begin{array}{c}\text { Articles/6 } \\
\text { Author }\end{array}$ & $\begin{array}{c}\text { Articles/7 } \\
\text { Author }\end{array}$ & $\begin{array}{c}\text { Articles/More } \\
\text { than } 7 \text { Author }\end{array}$ & Total \\
\hline $2000-2001$ & 24 & 32 & 13 & 4 & - & 1 & - & 9 & 83 \\
\hline $2001-2002$ & 32 & 22 & 16 & 4 & 1 & 2 & 2 & 22 & 101 \\
\hline $2002-2003$ & 23 & 32 & 21 & 5 & 5 & 6 & - & 9 & 101 \\
\hline $2003-2004$ & 36 & 43 & 15 & 16 & 5 & 5 & 2 & 20 & 142 \\
\hline $2004-2005$ & 42 & 24 & 26 & 14 & 2 & 3 & 4 & 5 & 120 \\
\hline $2005-2006$ & 73 & 31 & 31 & 21 & 9 & 4 & 1 & 6 & 176 \\
\hline $2006-2007$ & 67 & 32 & 27 & 13 & 7 & 1 & 3 & 13 & 163 \\
\hline $2007-2008$ & 73 & 45 & 49 & 14 & 5 & 1 & 2 & 4 & 193 \\
\hline $2008-2009$ & 104 & 41 & 46 & 26 & 10 & - & 1 & 6 & 234 \\
\hline $2009-2010$ & 104 & 74 & 68 & 34 & 24 & 12 & 3 & 16 & 335 \\
\hline Total & $\mathbf{5 7 8}$ & 376 & 312 & 151 & 68 & 35 & 18 & 110 & 1648 \\
\hline Percentage & $\mathbf{3 5 . 0 7}$ & $\mathbf{2 2 . 8 2}$ & $\mathbf{1 8 . 9 3}$ & $\mathbf{9 . 1 6}$ & $\mathbf{4 . 1 3}$ & $\mathbf{2 . 1 2}$ & 1.09 & 6.67 & 100.00 \\
\hline
\end{tabular}

The data in the present study revealed that there are 578 single authored articles, 376 articles having two authors, 312 articles collaborated by three authors, 151 articles having four authors, 68 articles having five authors, 35 articles having six authors, 18 articles having seven authors and 110 articles having more than eight authors. These data clearly demonstrates that researchers prefer to do work in collaboration. There are 1070 papers which were written by two or more authors where as only 578 articles belong to single category. The ratio of collaboration work was found to be high than the single author working i.e. the ratio between team work and solo author work is about 578:1. Table 1 represented the productivity pattern of authors. It was found that 578 authors preferred to work solely which is $35.07 \%$ i.e. highest percentage of the total work, when percentage of single authorship was compared with the percentage of multiple authorship. Only 578 authors prefer to work as single author. Two authors constituted $22.82 \%$ with 376 papers. Three authors constituted $18.93 \%$ with 312 papers. Four authors constituted $9.16 \%$ with 151 papers. Five authors constituted $4.13 \%$ with 68 articles. Six authors constituted $2.12 \%$ with 35 articles. Seven authors constituted $1.09 \%$ with 18 articles and lastly equal to eight or more than eight $6.67 \%$ with 110 papers. The data clearly depicted that the domination of multiple authorship trend over single authorship trend.

Data collected are presented in table 2, no. of single authored papers denoted by NSA and no. of multi authored papers denoted by the term NMA. Each year shows that multi authorship predominant over single authorship. NMA and NSA values are calculated for each year and it was found that highest percentage of NMA articles is $77.23 \%$ in the year 2002-2003 and lowest percentage is $55.56 \%$ in 2008-2009. Over all NSA paper constituted 35.07\% whereas NMA papers constituted $64.93 \%$ figure 1 showed comparison of percentage of single authored papers and multi authored papers. 


\begin{tabular}{|l|c|c|c|c|c|}
\hline \multicolumn{7}{|c|}{ Table 2: Single Authorship Vs Multiple Authorship } \\
\hline \multirow{2}{*}{ Year } & Single Author & \multicolumn{2}{c|}{ Multiple Authors } & \multirow{2}{*}{ Total Papers } \\
\cline { 2 - 5 } & Paper & Percentage & Paper & Percentage & \\
\hline $2000-2001$ & 24 & 28.92 & 59 & 71.08 & 83 \\
\hline $2001-2002$ & 32 & 31.68 & 69 & 68.32 & 101 \\
\hline $2002-2003$ & 23 & 22.77 & 78 & 77.23 & 101 \\
\hline $2003-2004$ & 36 & 25.35 & 106 & 74.65 & 142 \\
\hline $2004-2005$ & 42 & 35.00 & 78 & 65.00 & 120 \\
\hline $2005-2006$ & 73 & 41.48 & 103 & 58.52 & 176 \\
\hline $2006-2007$ & 67 & 41.10 & 96 & 58.90 & 163 \\
\hline $2007-2008$ & 73 & 37.82 & 120 & 62.18 & 193 \\
\hline $2008-2009$ & 104 & 44.44 & 130 & 55.56 & 234 \\
\hline $2009-2010$ & 104 & 31.04 & 231 & 68.96 & 335 \\
\hline Grand Total & $\mathbf{5 7 8}$ & $\mathbf{3 5 . 0 7}$ & $\mathbf{1 0 7 0}$ & $\mathbf{6 4 . 9 3}$ & $\mathbf{1 6 4 8}$ \\
\hline
\end{tabular}

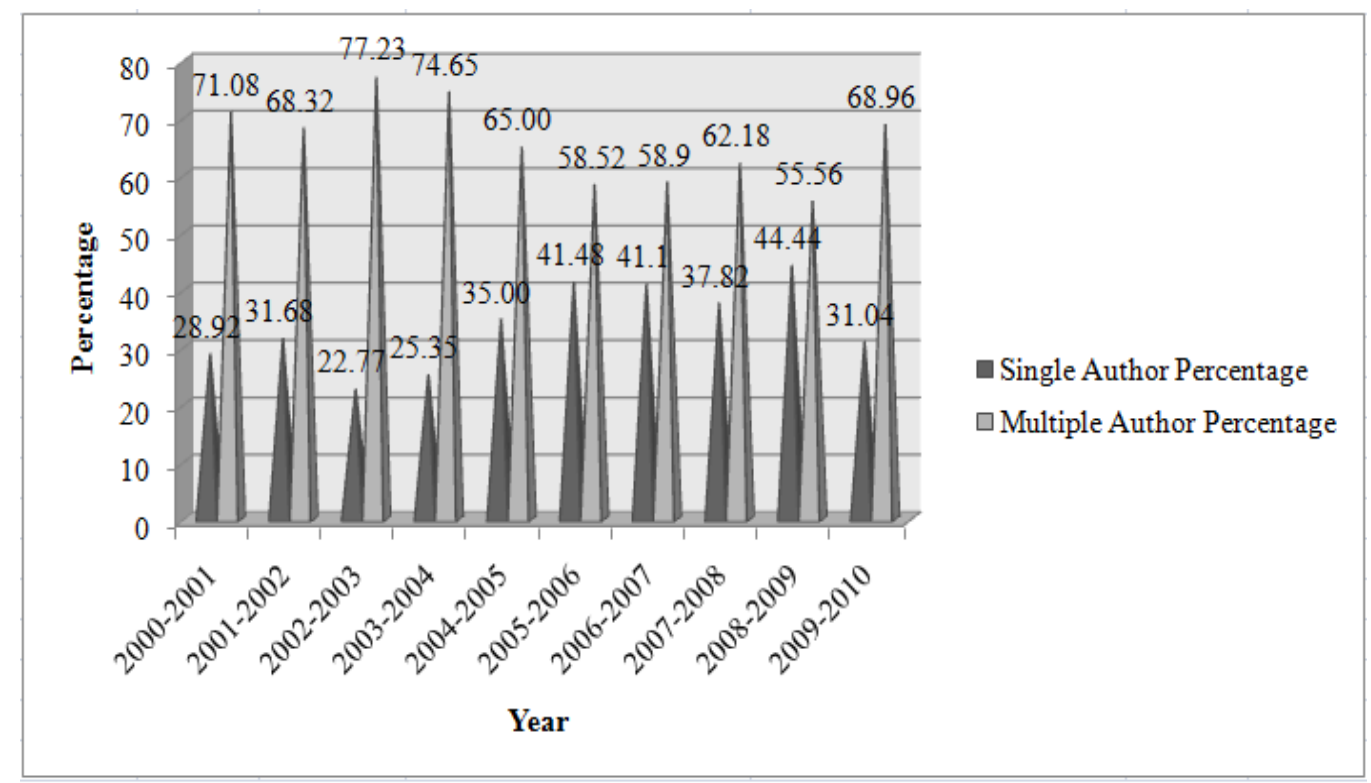

Figure 1. Single Author Vs Multiple Authors

The degree of collaboration can be calculated by the formula given below:

Degree of Collaboration $(\mathrm{C})=$ No. of Multiple Authors (NMA)/ \{No. of Multiple Authors (NMA) + No. of Single Authors (NSA)

By using this formula the degree of collaboration has been calculated and provided in table 3 . The degree of collaboration was calculated for 10 years. It showed that the highest degree of collaboration is $0.77 \%$ in $2002-2003$ and the least degree of collaboration is 0.56 in the year 20082009. Average degree of collaboration which is 0.65 shows faculty members in NEHU preferred team work in research. Figure 2, represents the degree of collaboration during 2000- 2010. 


\begin{tabular}{|c|c|c|c|}
\hline \multicolumn{4}{|c}{ Table 3. Degree of Collaboration in NEHU } \\
\hline Year & $\begin{array}{c}\text { Number of } \\
\text { Single Author } \\
\text { (NSA) }\end{array}$ & $\begin{array}{c}\text { Number of } \\
\text { Multiple Author } \\
\text { (NMA) }\end{array}$ & $\begin{array}{c}\text { Degree of Collaboration } \\
\text { C = NMA } / \text { (NMA + } \\
\text { NSA) }\end{array}$ \\
\hline $2000-2001$ & 24 & 59 & 0.71 \\
\hline $2001-2002$ & 32 & 69 & 0.68 \\
\hline $2002-2003$ & 23 & 78 & 0.77 \\
\hline $2003-2004$ & 36 & 106 & 0.75 \\
\hline $2004-2005$ & 42 & 78 & 0.65 \\
\hline $2005-2006$ & 73 & 103 & 0.59 \\
\hline $2006-2007$ & 67 & 96 & 0.59 \\
\hline $2007-2008$ & 73 & 120 & 0.62 \\
\hline $2008-2009$ & 104 & 130 & 0.56 \\
\hline $2009-2010$ & 104 & 231 & 0.69 \\
\hline Grand Total & $\mathbf{5 7 8}$ & $\mathbf{1 0 7 0}$ & $\mathbf{0 . 6 5}$ \\
\hline
\end{tabular}

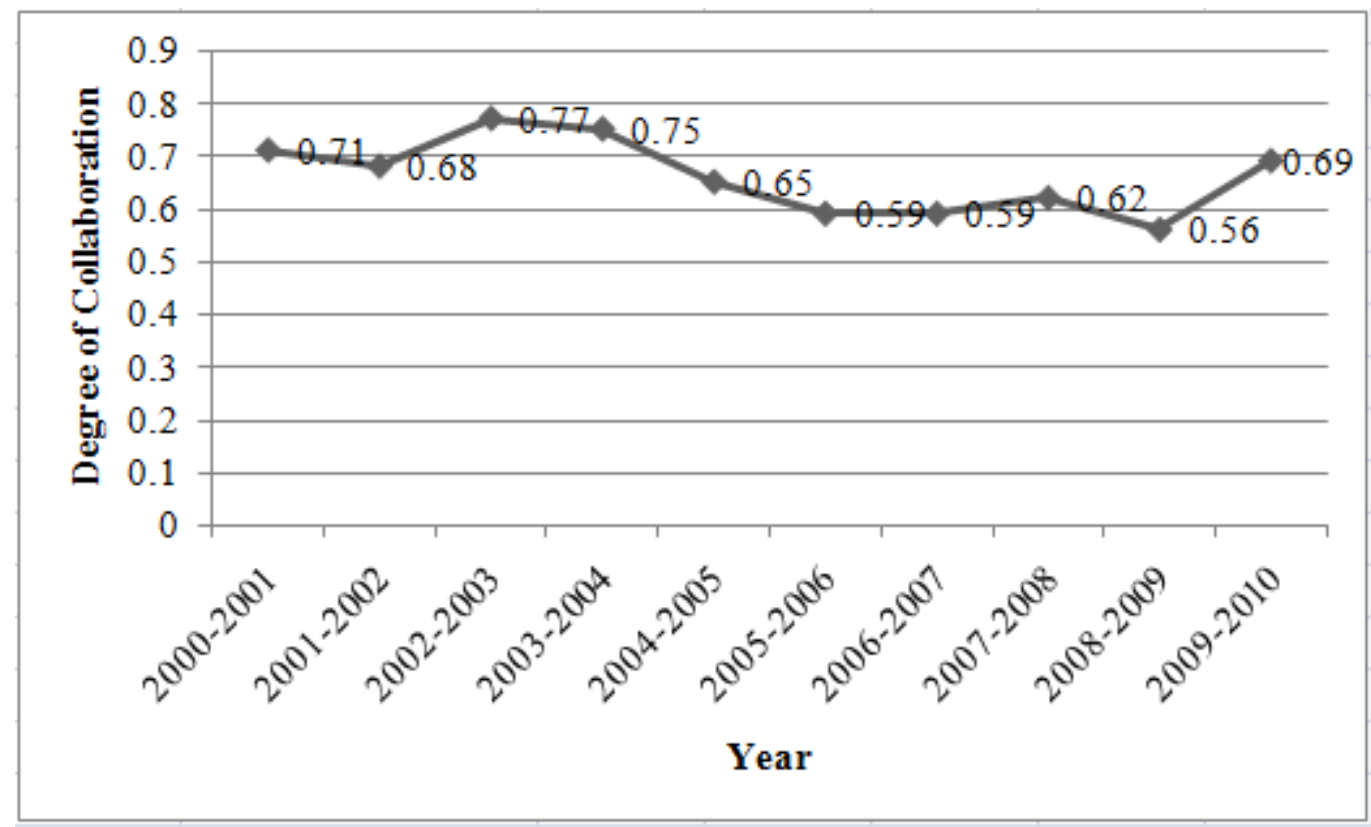

Figure 2. Degree of Collaboration in NEHU

Average no. of Articles was calculated in table 4 and it is seen that the average no. of authors per article varies from 2.47 in 2000-2001 to 2.89 in 2009-2010. Highest average authorship is observed in 2001-2002 i.e. 3.44 whereas lowest average authorship in 2009-2010 which is 2.29. In 10 years from 2000 to 2010 the average no. of authors per paper is 2.72. Figure 3 showed the graphical representation of average no. of authors per articles. 
Table 4. Average No. of Authors per Paper in NEHU

\begin{tabular}{|l|c|c|c|}
\hline Year & Total Papers (P) & Total Authors (A) & $\begin{array}{c}\text { Average No. of Authors } \\
\text { per Paper AAP=A/P }\end{array}$ \\
\hline $2000-2001$ & 83 & 205 & 2.47 \\
\hline $2001-2002$ & 101 & 347 & 3.44 \\
\hline $2002-2003$ & 101 & 303 & 3.00 \\
\hline $2003-2004$ & 142 & 460 & 3.24 \\
\hline $2004-2005$ & 120 & 288 & 2.40 \\
\hline $2005-2006$ & 176 & 438 & 2.49 \\
\hline $2006-2007$ & 163 & 441 & 2.71 \\
\hline $2007-2008$ & 193 & 443 & 2.30 \\
\hline $2008-2009$ & 234 & 535 & 2.29 \\
\hline $2009-2010$ & 335 & 969 & 2.89 \\
\hline
\end{tabular}

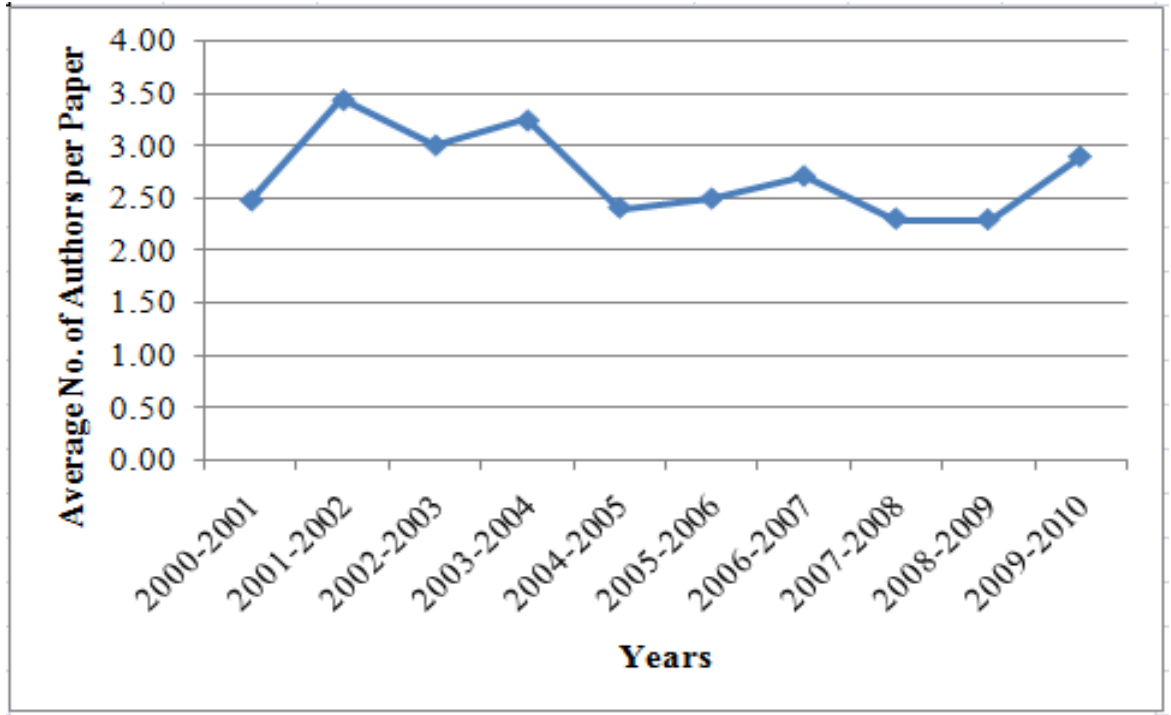

Figure 3. Average No. of Authors per Paper

\section{CONCLUSION}

The study has identified a clear trend towards collaborative research in North Eastern Hill University. In other words, NEHU faculty members prefer to conduct research in collaboration. The degree of collaboration is high and multi authorship is prominent in the NEHU. The ratio of collaboration work was found to be high than the single author working but when comparing individually solo work lead the distribution with $35.07 \%$ that is 578 articles, follows by $22.82 \% 376$ articles, the least distribution is articles with seven authors which contributes to only $1.09 \%$ 18 articles.

\section{REFERENCES}

[1] K. B. Jain, \& S. Kumar, "Indian Contributions to World Soybean Research: Measurement of Research Productivity of
Soybean Scientists," presented at the $8^{\text {th }}$ International CALIBER, Goa University, Goa, 2011.

[2] E. R. Lai, "Collaboration: A literature review," Pearson Research Report, 2, 2011.

[3] http://www.ijsrp.org/research-paper-0313/ijsrp-p15122.pdf, [Accessed 1 July 2015] I. Panda, B. Maharana, \& D. C. Chhatar, "The Journal of Information Literacy: A Bibliometric Study," International Journal of Scientific and Research Publications, vol. 3(3), 2013.

[4] T. K. Park, "D-Lib Magazine: Its first thirteen years" D-Lib Magazine, vol.16 (1/2). 2010.

[5] S. K. Patra, P. Bhattacharya, \& N. Verma, "Bibliometric Study of literature on bibliometrics," DESIDOC Bulletine of Information Technology, vol. 26(1), pp. 27-32. 2006.

[6] J. Roschelle, "Learning by collaborating: Convergent conceptual change,” Journal of the Learning Sciences, vol. 2, pp. 235-276. 1992.

[7] R. Sevukan, \& J. Sharma, "Bibliometric analysis of research output of biotechnology faculties in some Indian central universities,” DESIDOC Journal of Library \& Information Technology, vol. 28(6), pp. 11-20. 2008. 